\title{
PERCEPÇÃO E PREFERÊNCIA POPULAR POR ATRIBUTOS ESTÉTICOS E ECOLÓGICOS NA COMPOSIÇÃO DA ARBORIZAÇÃO DE RUAS
}

\author{
Rogério Bobrowski ${ }^{*}$, Daniela Biondi ${ }^{2}$ \\ ${ }^{1 *}$ Universidade Estadual do Centro-Oeste, Departamento de Engenharia Florestal, Irati, Paraná, Brasil - rogerio @irati.unicentro.br \\ ${ }^{2}$ Universidade Federal do Paraná, Departamento de Ciências Florestais, Curitiba,Paraná, Brasil - dbiondi@ufpr.br
}

Recebido para publicação: 09/09/2015 - Aceito para publicação: 10/12/2015

\begin{abstract}
Resumo
O planejamento da arborização de ruas é um processo complexo que envolve aspectos ambientais, o desenvolvimento urbano e a preferência popular. Esta pesquisa visou analisar a percepção e a preferência popular de atributos estéticos e ecoló gicos na composição da arborização de ruas. A obtenção dos dados se deu por meio de uma enquete eletrônica que continha diferentes perfis e formas de composição da arborização de ruas, bem como atributos de espécies florestais, como o porte e a floração. Os dados foram comparados por meio do teste de Mann-Whitney (opções dadas aos pares), por meio do teste de Kruskal-Wallis (mais de duas opções) e por meio de análise de correspondência canônica múltipla para mapeamento perceptual. Para o perfil transversal, não houve diferença significativa entre os votos dados às opções apresentadas. Com relação ao perfil longitudinal, preferiu-se aqueles com maior diversidade de espécies. Houve diferença significativa entre os votos dados às formas de composição, destacando-se aquele com disposição das espécies uma a uma. Com relação às características das espécies, houve diferença significativa entre os votos dados para as opções, com predominância da preferência por espécies de médio porte e pelas que apresentam floração de cor amarela.

Palavras-chave: Ecologia urbana; gestão da floresta urbana; paisagismo; silvicultura urbana.
\end{abstract}

\section{Abstract}

Popular perception and preference for aesthetic and ecological attributes on tree-lined street composition. The planning of tree-lined street is a complex process that involves environmental aspects, urban development and popular preference. This research aimed to analyze popular perception and preference for aesthetic and ecological attributes in the tree-lined street composition. Data were obtained by an electronic poll that contained different drawings and ways of tree-lined street composition, as well as attributes of forest species like size and flowering. Data were compared by Mann-Whitney test (options given in pairs), by Kruskal-Wallis test (more than two options) and by multiple canonical correspondence analysis for perceptual mapping. For the transversal view, there was no significant difference between votes given to the options presented. In relation to longitudinal view, people preferred those with more diversity of species. There was significant difference between votes given to the ways of composition, especially the one with species distributed one by one. In relation to species characteristics, there was significant difference between votes given to the options with predominance of preference for medium sized species and those that have yellow flowering.

Keywords: Landscaping; urban ecology; urban forestry; urban forest management

\section{INTRODUÇÃO}

Estudos que tenham por objetivo a percepção e co mpreensão popular do ambiente urbano são essenciais à gestão da arborização urbana (QUADROS; FREI, 2009), pois tendem a expressar os anseios, preferências, satisfações e insatisfações dos usuários dos espaços públicos (áreas verdes ou arborização de ruas) em relação aos elementos da composição que afetam a qualidade de vida e o bem-estar social (SCHROEDER et al., 2006; LACERDA et al., 2010; ZHENG, 2011).

Um desses elementos de composição são as plantas, as quais se destacam devido à sua importância no ambiente urbano (SCHROEDER et al., 2006), por contribuírem com a qualidade visual das ruas, o que, geralmente, engrandece o julgamento da qualidade visual feito pelas pessoas (WOLF, 2009). Is so reforça as afirmações de Zhang e Zheng (2011) de que a qualidade mais importante das árvores urbanas é a melhoria da aparência de uma comunidade ou bairro. Nesse sentido, pode-se afirmar que a preferência por uma determinada paisagem pode estar relacionada às características físicas da vegetação, como a coloração da folhagem, a altura dos elementos e a densidade da sua composição (KENDAL et al., 2008; WHITE; GATERSLEBEN, 2011).

Zhang e Zheng (2011) a firmam que as árvores e os espaços verdes contribuem significativamente com a qualidade de vida das comunidades urbanas, pois são componentes importantes da infraestrutura verde das

FLOREST A, Curitiba, PR, v. 46, n. 1, p. 123 - 133, jan. / mar. 2016.

Bobrowski, R.; Biondi, D.

ISSN eletrônico 1982-4688

DOI: $10.5380 /$ rf.v46il.43013 
cidades e proporcionam uma variada gama de benefícios, da mes ma forma que aqueles ofertados pelas demais infraestruturas urbanas, como os sistemas de coleta de esgoto, de distribuição da água e de transmissão de energia. Entretanto, não apenas a qualidade e a funcionalidade das infraestruturas influenciam a afeição e a preferência por uma cidade, mas também a qualidade estética é fator crucial (WEBER et al., 2008). Com re lação à percepção do ambiente, Tuan (2012) afirma que é variada a maneira como as pessoas a manifestam, mas que existe um padrão na forma de percepção das pessoas.

As árvores plantadas nas calçadas, por serem estruturas dinâmicas, refletem as mudanças sazonais e requererem manutenção, aguçam a percepção das pessoas e podem incitar duas formas distintas de sentimentos: a alegria, pelos benefícios que podem trazer, e a repulsa, por serem intrusas em espaços particulares (RAE et al., 2010). Lohr e Pearson-Mims (2006) afirmam que a interação passiva com plantas tem sido associada a muitos benefícios, incluindo redução do estresse, melhoria da saúde e recuperação da fadiga mental. Quadros e Frei (2009), em simulação da arborização de uma avenida comercial desprovida de vegetação arbórea, na cidade de Assis (SP), constataram que a população reconheceu a importância da arborização para a melhoria da qualidade visual da avenida e dos benefícios a mbientais associados.

A análise da percepção e preferência por atributos da arborização de ruas, por me io de enquetes, assume importância pela busca de informações sobre as expectativas populares a respeito do assunto e sobre a percepção estética e ambiental da população, pois, de acordo com Biondi e Althaus (2005), o sucesso de qualquer projeto de arborização só é alcançado com a corresponsabilidade da população, que deve estar ciente da importância das árvores na via pública, dos custos para sua manutenção e da necessidade de monitoramento público e popular, a fim de coibir atos de vandalismo. Para Zhang e Zheng (2011), a busca e o compartilhamento de informações a respeito das atitudes populares para com as árvores urbanas e da vontade popular em contribuir financeiramente são duas diretrizes estratégicas necessárias à facilitação de programas de financiamento da silvicultura urbana. Em geral, a simu lação virtual de paisagens é uma das formas que são usadas para analisar a preferência das pessoas por lugares e elementos componentes da paisagem (HEYMAN, 2012).

Nesse sentido, verifica-se que há muitos trabalhos de percepção ambiental que tratam da análise da arborização urbana e das preferências dos cidadãos, porém Zheng (2011) afirma que há pouca informação sistematizada a respeito das preferências públicas sobre as características das árvores e a configuração espacial delas em ambientes urbanos. Com relação a isso, Weber et al. (2008) afirmam que para os departamentos públicos de planejamento é crescente a importância da compreensão dos parâmetros que influenciam o julgamento na percepção visual dos espaços urbanos.

Portanto, a hipótese lançada para esta pesquisa foi a de que é possível buscar referências ao planejamento da arborização de ruas a partir da preferência popular. Nes se sentido, os objetivos desta pesquisa foram analisar a percepção e a preferência popular com relação a atributos estéticos e ecológicos da composição da arborização de ruas, prioritariamente sobre a forma de composição dos perfis (transversal e longitudinal) da rua e das características das espécies florestais que podem ser utilizadas (porte e floração).

\section{MATERIAL E MÉTODOS}

Para caracterizar e analisar a percepção e a preferência popular, foi elaborada uma enquete eletrônica com questionário estruturado, a qual continha imagens e textos a respeito de informações pessoais relacionadas ao tema, formas de composição da arborização de ruas em perfil e planta baixa e características das espécies florestais que podem ser utilizadas. A pesquisa online, via enquete, é caracterizada como "júri voluntário" (volunteer panels) do tipo não probabilístico, em que as pessoas escolhem se querem ou não participar, após se deparar com u ma solicitação online (FRICKER, 2008).

A enquete apresentada ao público e intitulada "Planejamento participativo da composição arbórea nas vias públicas de uma cidade" foi disponibilizada, entre 09/05/2013 e 09/11/2013, no endereço <https://www.onlinepesquisa.com/s/194d6ca> e divulgada em listas de e-mail e redes sociais. Para a participação na enquete não havia restrição de gênero, escolaridade ou formação técnica relacionada ao tema da pesquisa.

No questionário estruturado constava um total de 27 questões, sendo 11 sobre as pectos gerais pessoais e 16 sobre os atributos de composição da arborização de ruas, com as respectivas opções de resposta às escolhas feitas. Do total, cinco questões tratavam sobre informações gerais das pessoas (gênero, idade, escolaridade, formação técnica e disciplinas cursadas com relação à arborização de ruas), duas questões versavam sobre o perfil profissional de re lação co m a arborização de ruas (se atuava em algu m aspecto da arborização e qual o tipo de relação com a arborização de ruas), três questões abordavam a cidade do respondente (cidade, estado e qualidade da arborização de ruas da cidade) e uma questão estava relacionada à vontade do respondente em participar de trabalho voluntário sobre a coleta de dados para cadastro e avaliação da arborização de ruas. Para as 
questões sobre os atributos, foram feitas figuras representando os perfis de rua arborizada, com as seguintes combinações: duas tratavam do perfil transversal de composição da arborização (dois perfis diferentes, correspondentes a um corte da rua apresentando os dois trechos de calçada e a pista de rolamento - Figura $1 \mathrm{~A}$ e 1C), seis recaíam sobre o perfil longitudinal de composição da rua (três perfis diferentes correspondentes a um corte da rua apresentando um trecho contínuo de calçada - Figura 1B e 1D), duas sobre a forma de composição (alternadas uma a u ma ou duas a duas - Figura 1B e 1D), duas sobre o tipo de vista de topo ou visão de cima das copas (tipo de composição em planta baixa), duas sobre o porte da espécie arbórea (três opções) e duas sobre a floração da espécie arbórea (três opções). Com relação ao perfil longitudinal (trecho de uma calçada ao longo de uma quadra), foram elaboradas três questões distintas, de forma a promover a combinação entre dois perfis de cada vez, de três opções elaboradas (perfis longitudinais 1, 2 e 3).

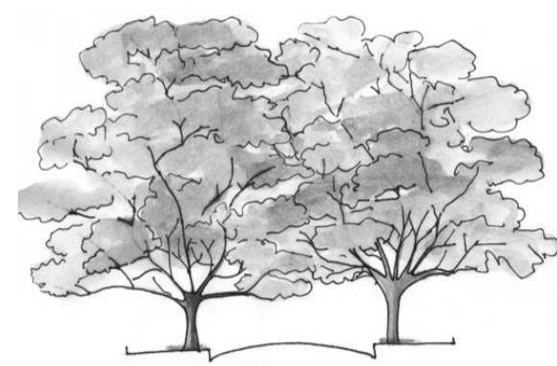

A

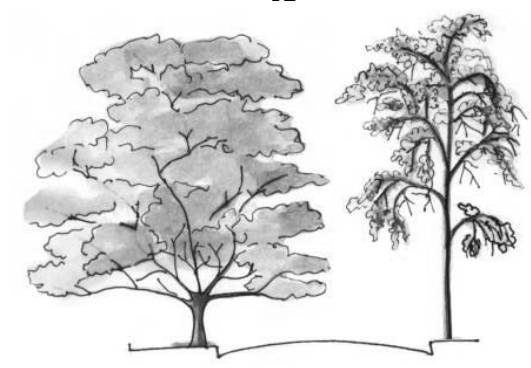

C

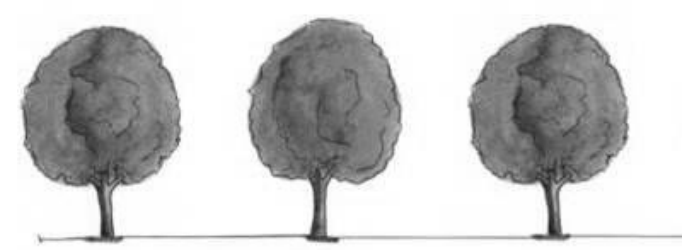

B

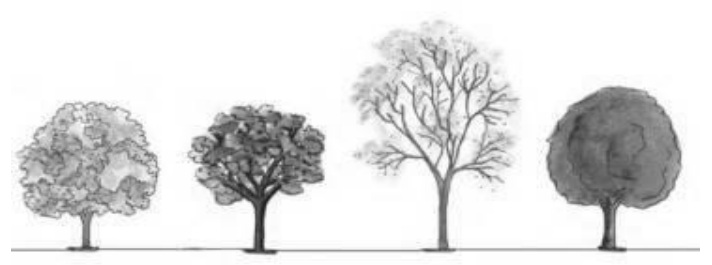

D

Figura 1. Representação dos perfis transversal $(A, C)$ e longitudinal $(B, D)$ apresentados na enquete.

Figure 1. Transversal $(A, C)$ and Longitudinal $(B, D)$ view representation presented in the survey.

Para possibilitar as análises estatísticas e melhorar a visualização perceptual, as escolhas feitas para cada forma de composição da arborização e para as características das espécies foram distribuídas em classes de faixa etária. As comparações das opções aos pares foram feitas por meio do Teste de Mann-Whitney (W), a partir do número de votos dados a cada uma delas em cada classe de faixa etária, e aquelas com mais de três opções foram comparadas por meio do Teste de Kruskal-Wallis, todas realizadas via pacote "stats" do software R.

As questões e respectivas respostas de justificativa também foram analisadas por meio de um mapa perceptual obtido com Análise de Correspondência Canônica Múltipla via pacote "ca" do software R, a fim de verificar correspondências entre as opções dos respondentes e extrair mais informações a respeito de suas percepções dos atributos estéticos e ecológicos da arborização de ruas.

\section{RES ULTADOS E DISCUSSÃO}

Ao todo foram obtidas 378 participações no trabalho realizado, porém apenas 352 pessoas responderam completamente às questões da enquete. A partir desse número de participantes é que se procedeu à análise das respostas. De acordo com Alreck e Settle (2004), para uma amostra de no mínimo 300 pessoas há 95\% de probabilidade de que a variação do erro seja menor que $10 \%$ do valor da méd ia a mostral, para qualquer tipo de entrevista (survey) adotada para análise de atitudes ou comportamentos. Entretanto, há que se considerar que a amostra obtida pode incluir indivíduos que são atípicos, o que tende a aumentar a variação do erro amostral (ALRECK; SETTLE, 2004).

A maior parte dos participantes afirmou ser do gênero feminino, com 183 pessoas $(51,99 \%)$, contra 169 pessoas do gênero masculino (48,01\%). Com relação aos gêneros, Tuan (2012) afirma que homens e mu lheres tendem a olhar diferentes aspectos do meio ambiente e a demonstrar atitudes distintas, principalmente nas culturas emque os papéis dos gêneros são bem distintos e marcantes.

FLOREST A, Curitiba, PR, v. 46, n. 1, p. 123 - 133, jan. / mar. 2016 
A faixa etária com participação mais expressiva foi aquela correspondente à faixa de 20-24 anos $(19,32 \%)$, seguida da faixa 25-29 anos (16,48\%). O nível de escolaridade mais participativo foi o "superior incomp leto" (28,69\%), seguido do nível "superior completo" (19,89\%) (Figura 2).

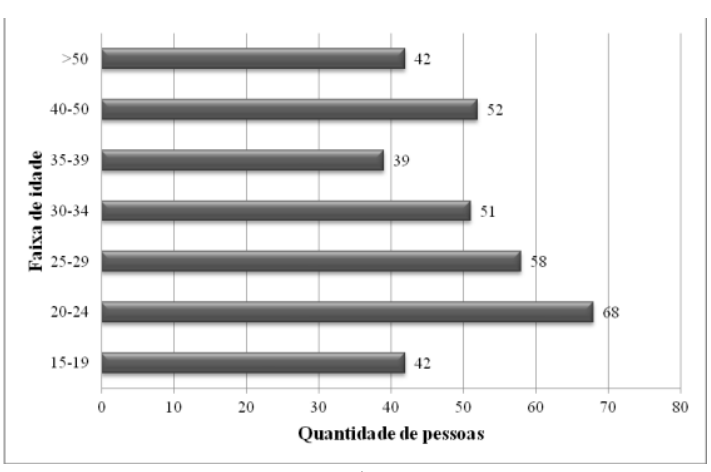

A

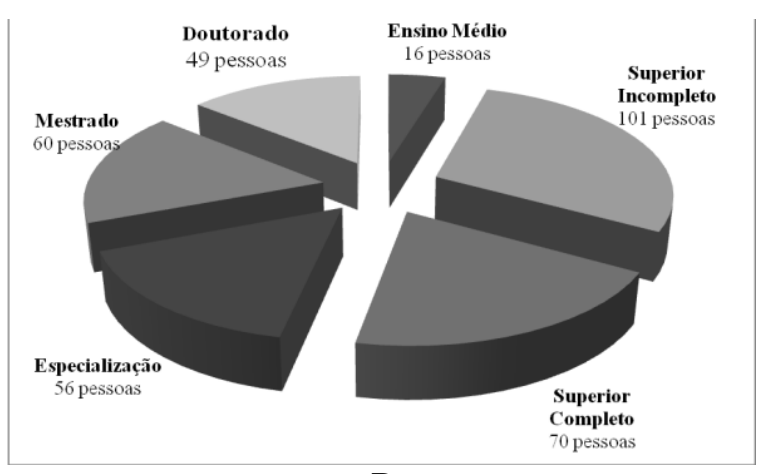

B

Figura 2. Distribuição dos participantes da enquete conforme faixa etária (A) e grau de instrução (B).

Figure 2. Distribution of survey respondents according to age group (A) and level of ed ucation (B).

Quanto à relação dos entrevistados com a arborização urbana, foi possível constatar que houve semelhança de distribuição de pessoas entre três classes de resposta (Rel5, Rel3 e Rel2), com as demais classes em menores proporções. As classes de relação com a arborização e respectiva frequência de pessoas foram: Rel1 - Não acho que eu tenha alguma relação com isso (4,26\%); Rel2 - Sou estudante de algumas disciplinas relacionadas ao as sunto (28,13\%); Rel3 - Sou profissional da área e estudei assuntos relacionados à área antes de iniciar os trabalhos (29,26\%); Rel4 - Sou profissional da área, mas não estudei nada relacionado antes de iniciar os trabalhos (8,81\%); Rel5 - Sou um leigo, curioso, admirador e/ou conhecedor de sua importância $(29,55 \%)$.

Com relação à questão "Você participaria como voluntário em trabalhos relacionados à arborização de ruas: coleta de dados para um estudo ou para cadastro e avaliação?", a maioria das pessoas $(70,17 \%)$ respondeu que "Sim, pois acredito que isso ajudaria a melhorar a condição e a paisagem de meu bairro". Essa informação é muito relevante ao processo de gestão da arborização de ruas, principalmente para fins de cadastro e avaliação geral das árvores quando se tem a intenção de obter um censo arbóreo e realizar o planejamento total da arborização de ruas em uma cidade, com redução de custos com mão de obra. Da mesma forma, permite a inclusão da população local no processo de planejamento, tornando-a parte do bem público, de propriedade coletiva, que deve trazer ben efícios ambientais, econômicos e estéticos os máximos possíveis, a partir dos recursos destinados a isso pela administração municipal. Ao inserir a população como parte da gestão, pode-se vislumbrar a redução de atos de vandalismo, por possibilitar um bom ato de cidadania e uma forma real de sensibilização da importância e dos custos desse bem público. Entretanto, isso é uma realidade incomum no Brasil, ou com relação à qual não se tem o hábito de valorizar e divulgar, principalmente por iniciativa do poder público, muito ao contrário do que ocorre nos Estados Unidos, onde existe um programa federal para apoiar ações comunitárias de silvicultura urbana (HAUER; JOHNSON, 2008), no qual a participação voluntária e seu treinamento es tão entre os critérios de ava liação para a concessão de suporte financeiro e técnico. Isso vai ao encontro das recomendações de Zhang e Zheng (2011), os quais afirmam que os gestores públicos devem intensificar as ações para ajudar o público a ter acesso aos programas de silvicultura urbana, encorajando-os a participar das atividades relacionadas.

\section{Perfil trans versal}

Com relação ao perfil transversal apresentado na enquete, a maioria dos participantes $(52,27 \%)$ optou pelo perfil transversal, composto por duas espécies diferentes (Figura 3B), em detrimento àquele composto por apenas uma espécie $(47,73 \%)$, entretanto não houve diferença significativa entre o nú mero de votos dados para os perfis $(\mathrm{W}=30,0 ; p$-valor $=0,5183)$.

Ainda quanto ao perfil transversal, para a pergunta "Por que você prefere esta forma de composição escolhida?", a resposta que obteve maior pontuação foi "Porque é mais diversificada" $(48,58 \%)$, seguida pelas respostas "Porque sombreia mais a rua" $(28,98 \%)$ e "Porque destaca melhor a espécie" $(22,44 \%)$.

Quando confrontadas as escolhas feitas pelos participantes com as respostas dadas como justificativa, por meio de análise de correspondência canônica (Figura 4), verificou-se que a classe de relação com a arborização Rel2 (estudantes) foi a que teve melhor correspondência com o perfil transversal um (PT1), com melhor associação à resposta "Porque sombreia mais a rua". Com relação ao perfil transversal dois (PT2), 
constatou-se correspondência com as classes de relação Rel3 (profissional que estudou a respeito) e Rel4 (profissional que não estudou a respeito), com melhor as sociação à resposta "'Porque é mais diversificada".

As respostas e correspondências obtidas demonstram que os participantes da enquete, ao se analis ar os perfis transversais, conseguiram justificar apropriadamente as escolhas feitas, pois o perfil transversal um, pela composição feita, sombreia mais a rua, ao passo que o perfil transversal dois é mais diversificado e destaca me lhor cada u ma das es pécies, devido ao contraste de cor, forma, te xtura e tamanho.

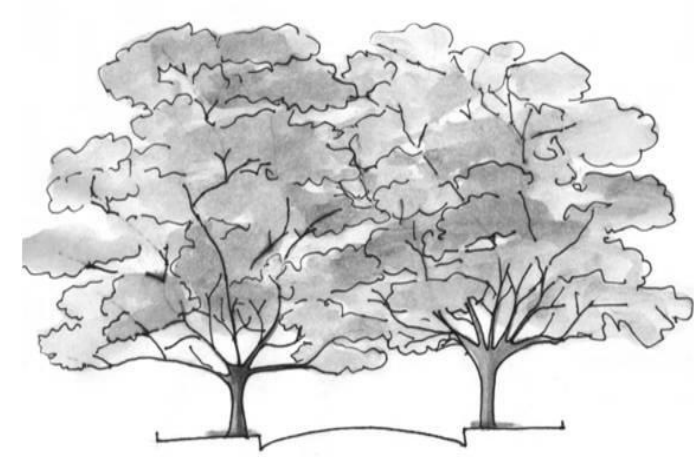

A

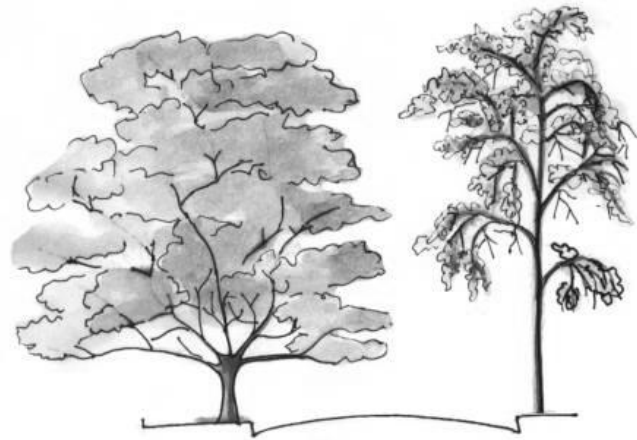

B

Figura 3. Opções de composição do perfil transversal: em (A), apenas uma espécie; em (B), duas espécies florestais.

Figure 3. Options for transversal view composition: in (A) only one species and in (B) two forest species.
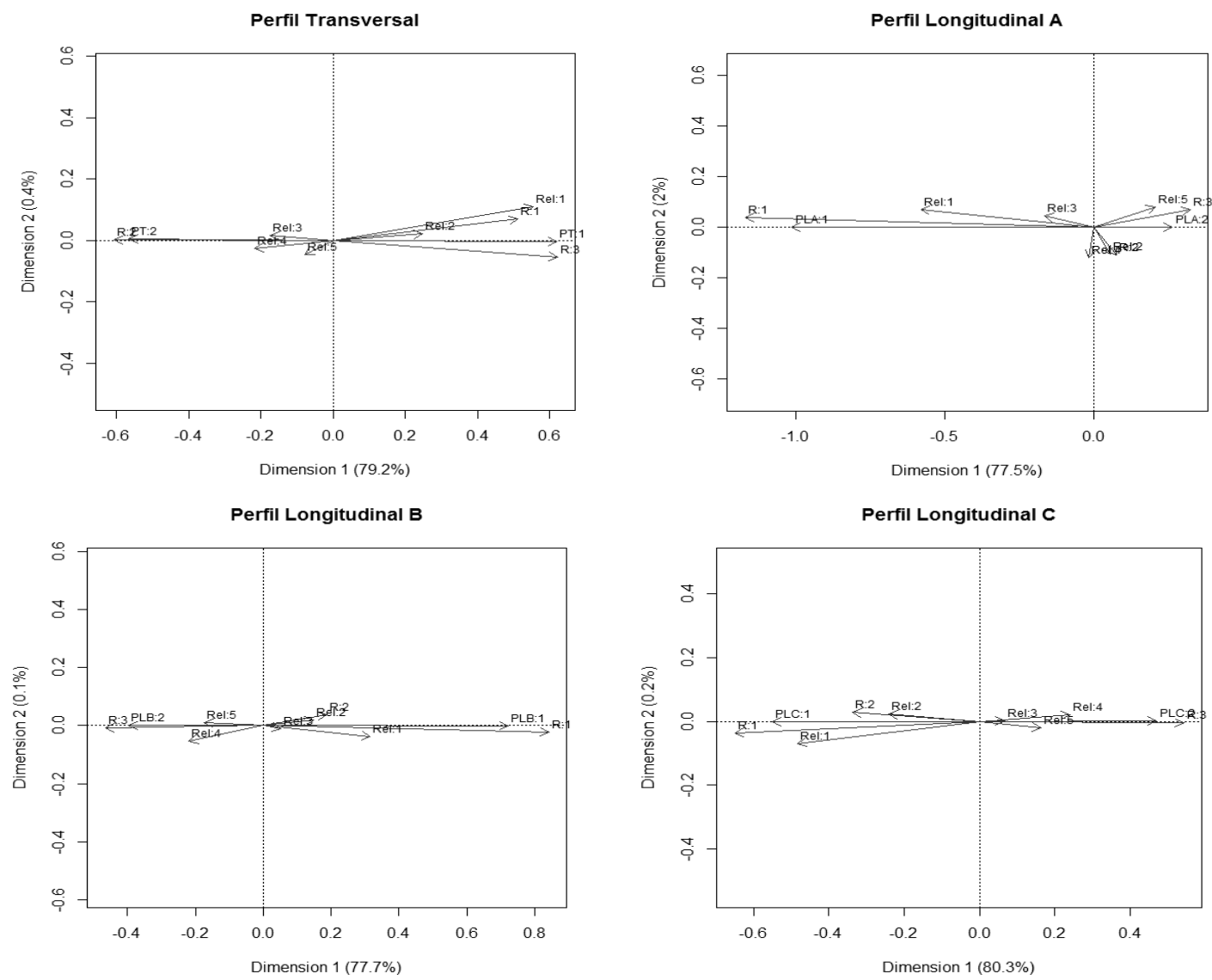

FLOREST A, Curitiba, PR, v. 46, n. 1, p. 123 - 133, jan. / mar. 2016.

Bobrowski, R.; Biondi, D.

ISSN eletrônico 1982-4688

DOI: $10.5380 /$ rf.v46il .43013 

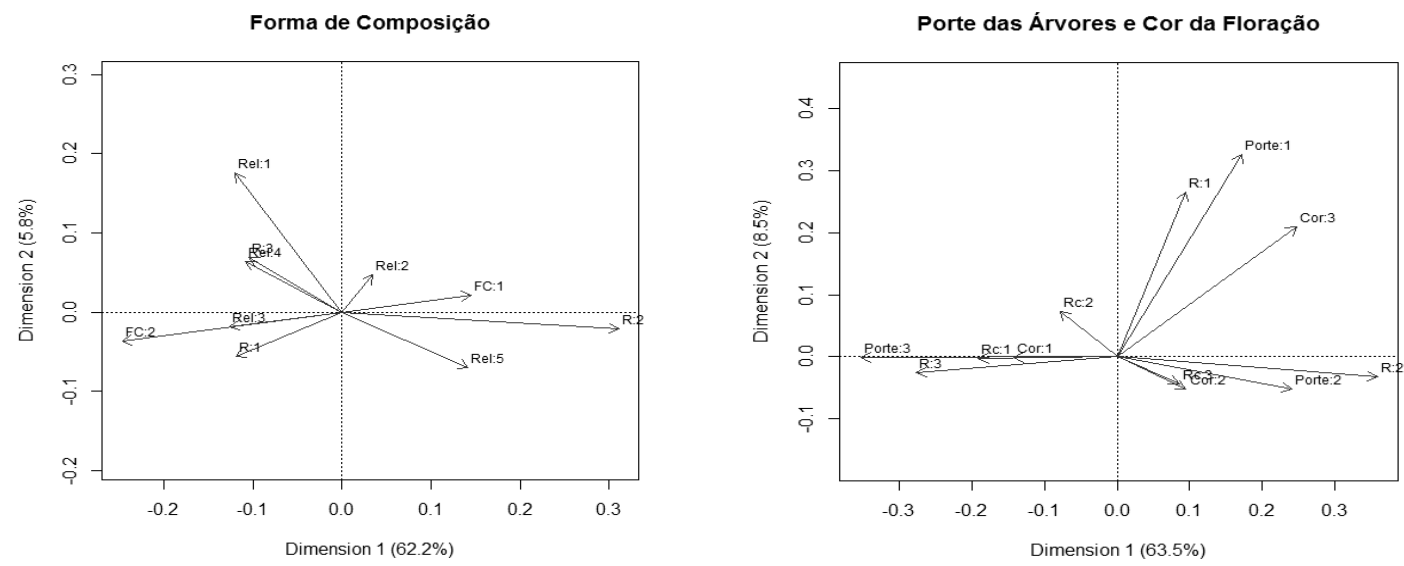

Figura 4. Representações gráficas da correspondência canônica múltipla entre diferentes atributos de composição da arborização de ruas, com respectivos valores de inércia nas dimensões 1 e 2, em que: PT (Perfil transversal, 1 e 2), PLA (Comparação entre perfis longitudinais 1 e 2), PLB (Comparação entre perfis longitudinais 1 e 3), PLC (Comparação entre perfis longitudinais 2 e 3), FC (Formas de composição do perfil longitudinal), Porte (Porte das espécies arbóreas, 1-grande, 2-médio, 3pequeno), Cor (Cor da floração, 1-amarela, 2-rosa/arroxeada, 3-branca/creme), R (Respostas a cada tipo de comparação), Rel (Relação dos participantes com a arborização).

Figure 4. Graphic representations of multiple canonical correspondence among different attributes of tree-lined street composition, with respective values of inertia in dimensions 1 and 2, in that: PT (Transversal view, 1 and 2), PLA (Comparison between longitudinal views 1 and 2), PLB (Comparison between longitudinal views 1 and 3), PLC (Comparison between longitudinal views 2 and 3), FC (Ways of longitudinal view composition), Porte (Size of arboreal species, 1-large, 2-medium, 3-small), Cor (Flowering color, 1-yellow, 2-pin k/purple, 3-white/cream), R (Responses to each kind of comparison), $\operatorname{Rel}($ Relationship of people with tree-lined street).

Sommer et al. (1993), ao analisarem diferentes atributos da composição da arborização de ruas, observaram diferenças entre as preferências do grupo de pessoas que são leigas ao assunto da arborização e do grupo de pessoas que são técnicas do assunto. Isso reflete a necessidade de compatibilizar os anseios populares no planejamento e manejo da arborização de ruas, tomando o cuidado com as recomendações prontas contidas em manuais de arborização urbana. Da mes ma forma, Schroeder et al. (2006) demonstram preocupação com as generalizações a respeito dos resultados de pesquis as sobre atitudes frente à arborização de ruas, pois resultados obtidos em um país podem não ser os mesmos obtidos em outros, em decorrência de fatores culturais e geográficos. Em um país com extensão continental como o Brasil, com seus diferentes biomas e condições climáticas, is so se destaca como u m aspecto que merece atenção.

\section{Perfil longitudinal}

Para a combinação entre os perfis longitudinais 1 e 2 (Figura 5) houve mais votos para o perfil longitudinal $2(79,55 \%)$ em detrimento do perfil longitudinal $1(20,45 \%)$, com dife rença significativa entre as escolhas feitas $\left(\mathrm{W}=49,0 ; p\right.$-valor $\left.=2,11^{-3}\right)$. Da mesma forma, houve maior preferência pelo perfil longitudinal 3 $(64,49 \%)$ e m relação ao perfil $1(35,51 \%)$, sendo significativamente diferente o nú mero de votos dados a cada composição $\left(\mathrm{W}=48,0 ; p\right.$-valor $\left.=3,29^{-3}\right)$, bem como maior preferência do perfil longitudinal $3(53,98 \%) \mathrm{em}$ relação ao perfil $2(46,02 \%)$, sem dife rença significativa $(\mathrm{W}=33,5 ; p$-valor $=0,325)$.
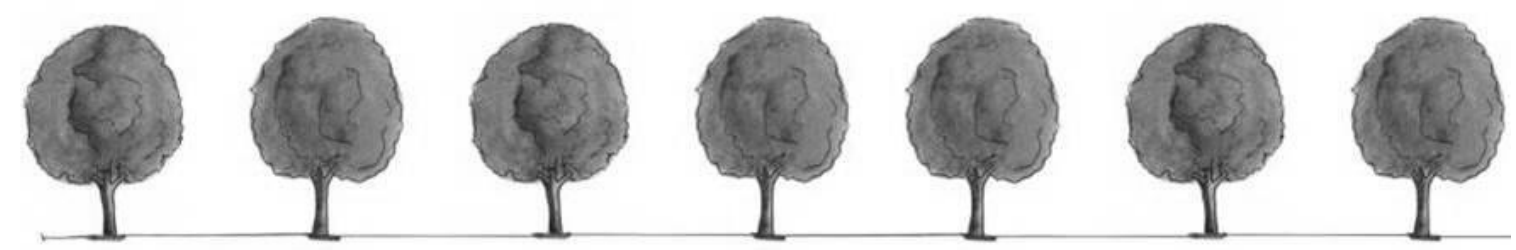

(1) 


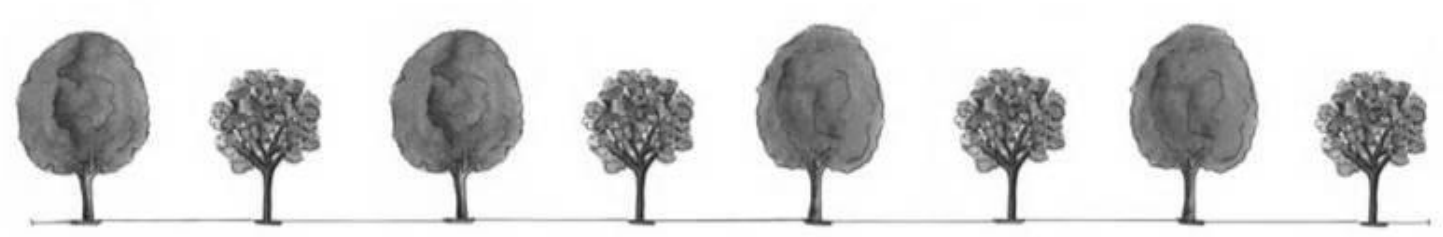

(2)
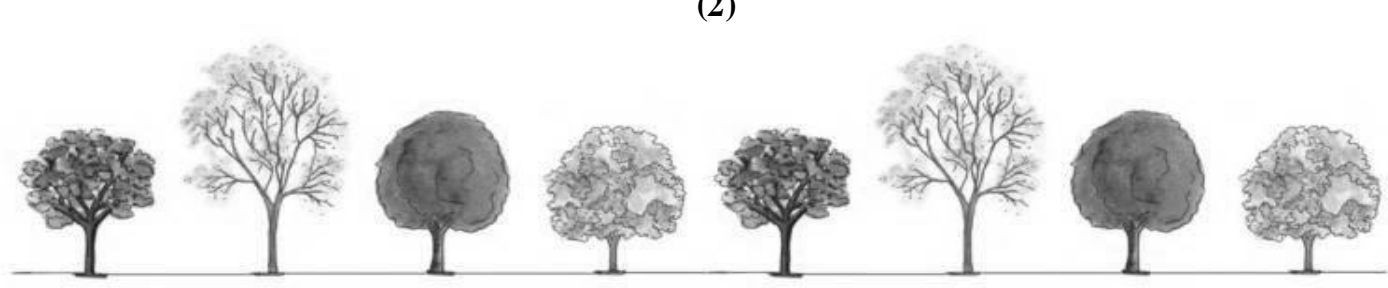

(3)

Figura 5. Opções de composição do perfil longitudinal co mapenas uma espécie (1), com duas espécies (2) e com quatro espécies (3).

Figure 5. Options of longitudinal view composition with only one species (1), with two species (2) and with four species (3).

Nas três comparações apresentadas, para justificar a escolha feita, os participantes optaram mais pela resposta "Porque representa uma rua mais diversificada", seguida pelas respostas "Porque representa melhor u m ritmo de composição" e "Porque é mais uniforme e destaca melhor a espécie", em variações porcentuais conforme o tipo de comparação de perfil.

Por meio da análise de correspondência entre as escolhas feitas pelos participantes e as respostas dadas como justificativa (Figura 4) constatou-se que para as três comparações apresentadas (Perfis longitudinais A, B e C) houve associação entre o perfil menos diverso e a resposta "Porque é mais uniforme e destaca melhor a espécie" (R1) e entre o perfil mais diverso e a resposta "Porque representa uma rua mais diversificada" (R3). Tais constatações são lógicas, coerentes e corretas, vis to que a uniformidade é plena na composição do perfil 1 (Figura 5) e os perfis 2 e 3 são mais diversos que o primeiro. Considerando-se o perfil longitudinal C, apesar de não haver diferença entre o número de votos dados a cada um deles, o perfil 2 , em comparação ao perfil 3 , destaca melhor os atributos estéticos de cada espécie (cor, forma, textura), não os diluindo em meio a um maior número de espécies com características morfológicas e estéticas diferentes.

Para os grupos de relação com a arborização de ruas, destacam-se os grupos formados por estudantes (Re12) e profissionais que estudaram a respeito (Re13), com melhor correspondência com os perfis menos diversos, ao passo que os grupos formados por profissionais que não estudaram a respeito (Rel4) e os leigos, admiradores da arborização (Re15), demonstraram melhor correspondência com os perfis mais diversos. No caso dos dois primeiros grupos de participantes (Rel2 e Re15), a correspondência observada pode decorrer da compreensão da necessidade de conciliar as práticas de manejo da arborização com a diversificação da composição florística, não esquecendo dos atributos estéticos, pois quanto mais diversa a composição, mais difícil se torna o controle dessas variáveis.

Ao se aceitar a composição da arborização de ruas com quatro espécies em um perfil longitudinal, co mo no perfil 3, além da dilu ição do efeito estético, pode-se incorrer em problemas de gerenciamento das operações de implantação e manutenção que devem ser levadas em consideração, pois cada espécie apresenta características morfológicas e ecofisiológicas distintas (tamanho, densidade de folhagem, queda de folhas, época de floração, tolerância a podas e emissão de brotações adventícias, entre outras). Apesar do apelo ambiental pela maior diversidade de espécies na arborização de ruas, deve-se ponderar as dificuldades de produção de mudas com qualidade para atender às expectativas de composição de um perfil como es se. Da mesma forma, deve-se atentar para o fato de que a adaptabilidade das espécies às condições de estresse urbano e a sua longevidade potencial também são fatores tão ou mais importantes que a diversidade de composição (RAUPP et al., 2006). Além disso, a maior diversidade de espécies nas ruas pode gerar uma diminuição do sentido de "unidade" com outros elementos urbanos, tais como: estilos arquitetônicos, cores, texturas e porte das estruturas (alturas).

\section{Forma de composição}

A avaliação da forma de composição dos perfis longitudinais com mais de uma espécie (Figura 6) demonstrou que $63,07 \%$ das pessoas preferiram a opção de composição "A" (espécies alternadas

FLOREST A, Curitiba, PR, v. 46, n. 1, p. 123 - 133, jan. / mar. 2016.

Bobrowski, R.; Biondi, D.

ISSN eletrônico 1982-4688

DOI: $10.5380 /$ rf.v46il 43013 
individualmente, u ma a u ma), a qual as sume significativa prefe rência em relação à outra opção (W $=2,0 ; p$-valor $=4,84^{-3}$ ). Dentre as respostas escolhidas como justificativa, destacou-se a opção "Porque há melhor percepção de ritmo na composição" (37,22\%), vindo em seguida as respostas "Porque as espécies ficam melhor destacadas (folhagem e floração)" (36,36\%) e "Porque há maior diversificação na co mposição" (26,42\%).

$\mathrm{O}$ aumento do número de espécies compondo um perfil longitudinal de forma alternada, uma a uma, tende a aumentar a diluição do efeito estético buscado, pois a percepção de ritmo na composição fica dificultada pelo maior distanciamento entre árvores da mesma espécie. Por outro lado, em composições feitas em grupos de quatro espécies ou mais, a alternância de um maior número de espécies na arborização pode acentuar a percepção do efeito estético de cada espécie e do rit mo de co mposição realizado.

Bobrowski e Biondi (2012) afirmam que, na arborização de ruas, sempre se buscam dois objetivos: a diversificação de espécies e a uniformidade de composição. Tais objetivos vão além da precaução quanto ao ataque de pragas e doenças pela simplificação florística e visam apresentar diferentes atributos estéticos das espécies (floração, textura de folhagem e forma de copa, dentre outros), principalmente pelo uso de princípios de composição paisagística, como o ritmo. Isso também é visto como uma técnica para facilitar as ações de manejo da arborização de ruas, por manter a mesma espécie em uma quadra ou rua, padronizando o tipo de equipamento a ser utilizado.

Por meio da figura 4, constata-se haver correspondência entre a opção de perfil com espécies alternadas duas a duas ou quatro a quatro (FC2) com o grupo de relação "profissionais que estudaram sobre a arborização urbana" (Rel3) e com a opção de resposta justificativa R1 "Porque as espécies ficam melhor destacadas (folhagem e floração)". Muito provavelmente, a prática e vivência da implantação, condução e manejo da arborização de ruas favoreceu a percepção acertada desses profissionais.
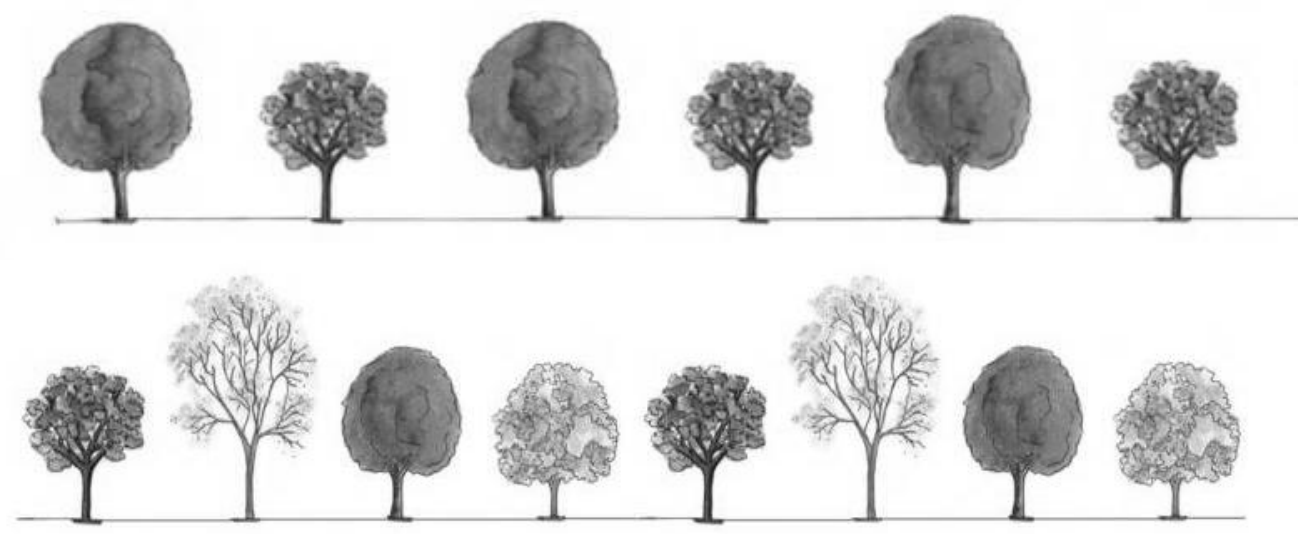

(A)
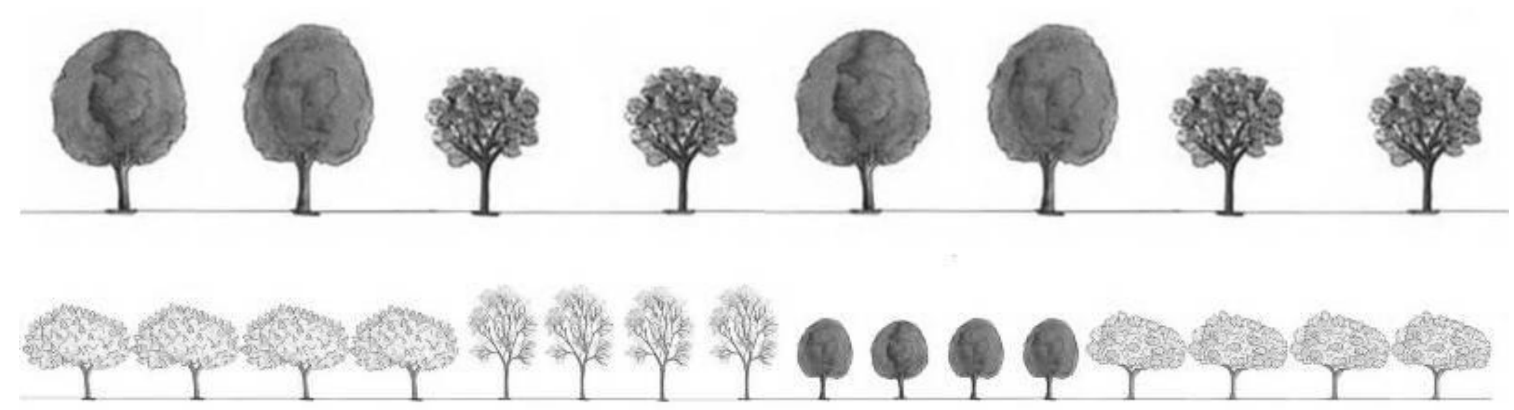

(B)

Figura 6. Formas de composição dos perfis longitudinais: (A) espécies alternadas individualmente, u ma a u ma; (B) espécies alternadas em grupo, duas a duas ou quatro a quatro.

Figure 6. Ways of longitudinal view composition: (A) species alternated individually, one by one; (B) species alternated in group, two by two or four by four. 


\section{Características das espécies}

Por meio da avaliação do porte das espécies florestais que podem ser utilizadas para a composição da arborização de ruas (Figura 7), foi possível constatar que 51,99\% dos participantes da enquete preferem espécies classificadas como de médio porte (exemplo: Lafoensia pacari - dedaleiro), seguidos por aqueles que preferem as de grande porte (exemplo: Tipuana tipu - tipuana), com 39,49\% das respostas, e por aqueles que preferem as árvores de pequeno porte (exemplo: Lagerstroemia indica - extremosa), com 8,52\%. Quanto a isso, foi constatada diferença significativa entre os votos dados para as classes de porte $\left(\chi^{2}=14,22 ; \mathrm{GL}=2 ; p\right.$-valor $=$ $\left.8,17^{-4}\right)$.

Souza et al. (2013), em pesquisa realizada na cidade de Alegre, ES, constataram que a maioria dos entrevistados demonstrou preferência por espécies de médio porte, por entenderem que elas reduzem conflitos com a fiação e as edificações. Porém os autores afirmaram que essa preferência também pode decorrer da influência dos costumes locais de convivência comespécies dessa classe de porte.

O inconveniente da escolha e priorização do uso de espécies classificadas como de médio porte é que, em condições de plantio sob rede de distribuição de energia elétrica, as árvores tendem a não ultrapassar o limite da rede de média tensão, tampouco a ficar abaixo da fiação de telecomunicações. Por conta disso, as manutenções com podas são constantes e duradouras, até o final do ciclo da árvore. Da mesma forma, mantém-se alterada e desequilibrada a conformação da arquitetura de copa, para atender aos parâmetros de proteção da rede.
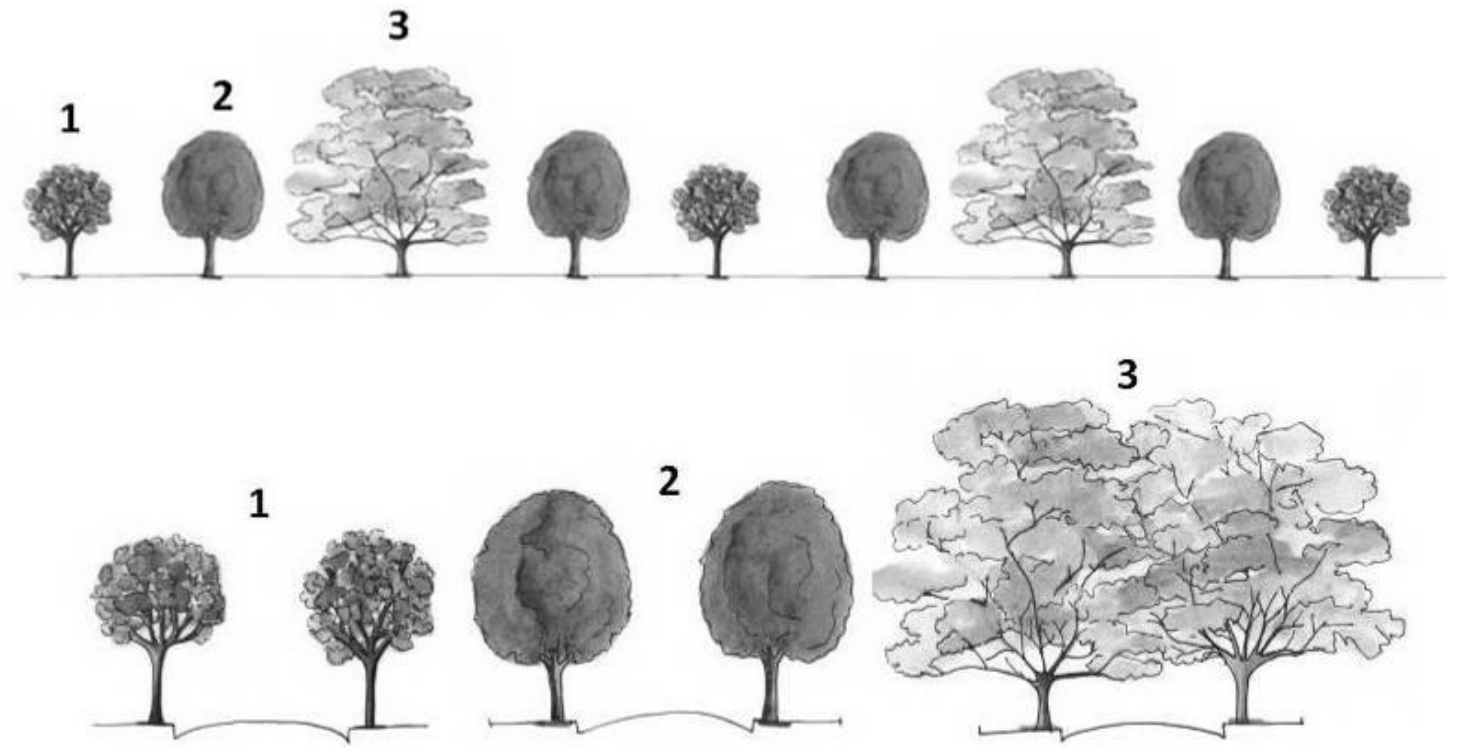

Figura 7. Diferentes representações do porte das árvores: 1-pequeno porte, 2-médio porte, 3-grande porte.

Figure 7. Different representations of trees size: 1-s mall sized, 2-mediu m sized, 3-large sized.

Por outro lado, Wolf (2009), ao simu lar diferentes formas de composição da arborização em u ma área comercial, constatou que árvores de grande porte foram associadas à alta preferência visual dos entrevistados, apesar da preocupação dos comerciantes quanto ao bloqueio da visualização da fachada dos estabelecimentos. Para a autora, essas espécies são uma opção de composição da arborização de ruas para contornar o problema, pois, ao crescerem e passarem pelas práticas de poda, tendem a desobstruir a fachada do comércio, ao contrário daquelas de pequeno porte, que permanecem obstruindo a visualização.

Dentre as respostas escolhidas como justificativa, a opção escolhida "Porque propicia mais vantagens ambientais (frescor, ventilação, sombra, dentre outras)" se destacou $(52,27 \%)$, vindo em seguida as respostas "Porque propicia mais segurança ao tráfego e aos pedestres" (37,78\%) e "Porque demonstra melhor o efe ito estético da espécie" (9,94\%).

A análise de correspondência canônica (Figura 4) demonstrou que houve coerência entre as respostas escolhidas como justificativa à opção de porte selecionada. Para o porte pequeno, houve correspondência com a resposta "Porque demonstra melhor o efeito estético da espécie", principalmente pelo grupo de pessoas que acreditam não ter nenhuma relação com a arborização (Rel1) e pelo grupo de pessoas declaradas como leigas, curiosas, admiradoras e conhecedoras da importância da arborização (Re15). Para o porte grande, houve correspondência com a resposta "Porque propicia mais vantagens ambientais (frescor, ventilação, sombra, dentre outras)", principalmente pelo grupo de estudantes de disciplinas relacionadas ao assunto (Re12), possivelmente

FLOREST A, Curitiba, PR, v. 46, n. 1, p. 123 - 133, jan. / mar. 2016.

Bobrowski, R.; Biondi, D.

ISSN eletrônico 1982-4688

DOI: $10.5380 /$ rf.v46il .43013 
por compreenderem os múltiplos benefícios que as árvores prestam como serviços ambientais no contexto urbano e por reconhecerem a importância das árvores de maior tamanho na ampliação destes. Essa correspondência observada se deve ao reconhecimento científico e acadêmico de que as es pécies de grande porte fornecem e maximizam os benefícios ambientais mais expressivamente que aquelas de pequeno porte (HEIMLICH et al., 2008; SYDNOR; SUBBURA YALU, 2011).

Quanto à preferência pela cor da floração, houve predominância dos participantes da enquete que optaram pela floração de cor amarela $(46,88 \%)$, seguidos por aqueles que optaram pela floração rosa/arro xeada $(42,33 \%)$ e branca/creme $(10,80 \%)$, com diferença significativa entre os votos dados para as cores apresentadas $\left(\chi^{2}=13,79 ; \mathrm{GL}=2 ; p\right.$-valor $\left.=1,01^{-3}\right)$.

Para Jalil et al. (2012), as cores influenciam o comportamento humano, suas decisões e sua saúde, afetando a vida humana fisicamente, fisiologicamente, psicologicamente e socialmente. A cor amarela, assim como as demais cores primárias, tende a estimular o sistema nervoso, sendo ideal para ambientes que exigem concentração (VALDEZ; MEAHRABIAN, 1994; TUAN, 2012), o que a torna interessante para compor a arborização de ruas e manter a atenção dos motoristas. Por outro lado, a cor rosa tende a induzir menor ansiedade e raiva (VALDEZ; MEHRABIAN, 1994). Em contraste com as cores frias e a monotonia cinza das ruas e avenidas, tende a destacar o ele mento vegetal e a chamar a atenção dos transeuntes.

Com relação à cor verde que predomina na copa das árvores na maior parte do ano, afirma-se que ela desempenha efeito calmante e redutor do estresse, mu ito provavelmente por ser u ma cor fria, caracterizada por comprimentos de onda curtos (JALIL et al., 2012).

Quanto aos motivos para escolha da cor da floração, verificou-se que a maioria das pessoas $(55,40 \%)$ indicou a opção "Porque ela se destacar mais na paisagem das ruas, contrastando melhor", 33,81\% a opção "Porque acredito que seja a mais bela" e 10,80\% a opção "Porque a maioria das espécies da região apresenta essa cor de floração". A opção que apresentou maior frequência de escolha dá indícios de que os participantes da enquete conseguem verificar princípios estéticos da vegetação, pois as cores apresentadas contrastam bem com a tonalidade cinzenta das ruas.

A análise de correspondência (Figura 4) demonstrou que, para a floração amarela, aquela mais escolhida, houve maior correspondência com a resposta "Porque a maioria das es pécies da região apresenta essa cor de floração". Muito provavelmente, a associação entre a cor amarela e a resposta indicada se deve à le mbrança da árvore símbolo do Brasil, o ipê-amarelo (SILVA et al., 2007), representado por diferentes espécies nas cinco regiões do país.

\section{CONCLUS ÕES}

- As pessoas reconheceram adequadamente alguns atributos estéticos de composição na arborização de ruas e conseguiram associar e justificar apropriadamente as opções e respostas dadas. Entretanto, não cons eguiram evidenciar as situações de composição em que o princípio de composição "ritmo" se dava de forma mais proeminente.

- Houve predominância de preferência por perfis de composição mais diversos, mas com espécies alternadas uma a uma, apesar da percepção de efeitos estéticos ocorrer com a repetição de elementos na composição dispostos lado a lado.

- Da mesma forma, as pessoas preferiram que a composição da arborização de ruas se desse com espécies de méd io porte e que possuísse floração de cor a marela.

\section{REFERÊNCIAS}

ALRECK, P. L.; SETTLE, R. B. The survey research handbook. 3. ed. New York: McGraw-Hill, 2004.

BIONDI, D.; ALTHAUS, M. Árvores de rua de Curitiba: cultivo e manejo. Curitiba: Fupef, 2005.

BOBROWSKI, R.; BIONDI, D. Caracterização do padrão de plantio adotado na arborização de ruas de Curitiba, Paraná. Revista da Socie dade Brasileira de Arborização Urbana, Piracicaba, v. 7, n. 3, p. 20 - $30,2012$.

FRICKER, R. D. Sampling methods for web and e-mail surveys. In: FIELDING, N.; LEE, R. M.; BLANK, G. The SAGE handbook of online research methods. Thous and Oaks: SA GE Publications, 2008, p. 195 - 217.

HAUER, R. J.; JOHNSON, G. R. Approaches within the 50 United States to meeting federal requirements for urban and community forestry assistance programs. Arboriculture \& Urban Forestry, Champaign, v. 34, n. 2, p. $74-83,2008$. 
HEIMLICH, J.; SYDNOR, T. D.; BUMGARDNER, M.; O'BRIEN, P. Attitudes of residents toward street trees on four streets in Toledo, Ohio, U.S. before removal of ash trees (Fraxinus spp.) fromemerald ash borer (Agrilus planipennis). Arboriculture \& Urban Forestry, Champaign, v. 34, n. 1, p. 47 - 53, 2008.

HEYMAN, E. Analyzing recreational values and management effects in an urban forest with the visitor-employed photography method. Urban Forestry \& Urban Greening, Amsterdam, v. 11, n. 3, p. 267 - 277, 2012.

JALIL, N. A.; YUNUS, R. N.; SAID, N. S. Environmental color impact upon human behavior: a review. Procedia - S ocial and Behavi oral Sciences, Amsterdam, v. 35, n. 5, p. 54 - 62, 2012.

KENDAL, D.; WILLIAMS, K.; ARMSTRONG, L. Preference for and performance of some Australian native plants grown as hedges. Urban Forestry \& Urban Greening, A msterdam, v. 7, n. 2, p. 93 - 106, 2008.

LACERDA, N. P.; SOUTO, P. C.; DIAS, R. S.; SOUTO, L. S.; SOUTO, J. S. Percepção dos residentes sobre a arborização da cidade de São José de Piranhas, PB. Revista da Sociedade Brasileira de Arborização Urbana, Piracicaba, v. 5, n. 4, p. 81 - 95, 2010.

LOHR, V. I.; PEARSON-MIMS, C. H. Responses to scenes with spreading, rounded, and conical tree forms. Environment and Behavi or, v. 38, n. 5, p. 667 - 688, 2006.

QUADROS, L. S.; FREI, F. Percepção ambiental dos residentes da cidade de Assis/SP com relação à arborização viária da Avenida Rui Barbosa. Revista da Sociedade Brasileira de Arborização Urbana, Piracicaba, v. 4, n. 2, p. 16 - 34, 2009.

RAE, R. A.; SIMON, G.; BRADEN, J. Public reactions to new street tree planting. Cities and the Environment, v. 3, n. 1, p. 1 - 21, 2010.

RAUPP, M. J.; CUMMING, A. B.; RAUPP, E. C. Street tree diversity in eastern north America and its potential for tree loss to exotic borers. Arboriculture \& Urban Forestry, Champaign, v. 32, n. 6, p. 297 - 304, 2006.

SCHROEDER, H.; FLANNIGAN, J.; COLES, R. Residents' attitudes toward street trees in the UK and U.S. communities. Arboriculture \& Urban Forestry, Champaign, v. 32, n. 5, p. 236 - 246, 2006.

SILVA, L. M.; MOCCELliN, R.; WEISSHEIMER, D. I.; ZBORALSKI, A. R.; FONSECA, L.; RODIGHIERO, D. A. Inventário e sugestões para arborização em vias públicas de Pato Branco/PR. Revista da Sociedade Brasileira de Arborização Urbana, Piracicaba, v. 2, n. 1, p. 100 - 108, 2007.

SOMMER, R.; GUENTHER, H.; BARKER, P. A.; SWENSON, J. P. Comparis on of four methods of street tree assessment. Journal of Arboriculture, Champaign, v. 19, n. 1, p. 27 - 34, 1993.

SOUZA, S. M.; CARDOSO, A. L.; SILVA, A. G. Estudo da percepção da população sobre a arborização urbana, no município de Alegre/ES. Revista da Sociedade Brasileira de Arborização Urbana, Piracicaba, v. 8, n. 2 , p. $68-85,2013$.

SYDNOR, T. D.; SUBBURA YALU, S. K. Should we consider expected environmental benefits when planting larger or smaller tree species? Ar boriculture \& Urban Forestry, Champaign, v. 37, n. 4, p. 167 - $172,2011$.

TUAN, Y. Topofilia: u mestudo da percepção, atitudes e valores do me io a mbiente. Londrina: Edue1, 2012.

VALDEZ, P.; MEHRABIAN, A. Effects of color on emotions. Journal of Experimental Psychology, Washington, v. 123, n. 4, p. 394 - 409, 1994.

WEBER, R.; SCHNIER, J.; JACOBSEN, T. Aesthetics of streetscapes: influence of fundamental properties on aes thetic judgments of urban space. Perceptual and Motor Skills, Missoula, v. 106, n. 1, p. 128 - 146, 2008.

WHITE, E. V.; GATERSLEBEN, B. Greenery on residential buildings: does it affect preferences and perceptions of beauty? Journal of Envir onmental Psychology, A msterdam, v. 31, n. 1, p. 89 - 98, 2011.

WOLF, K. L. Strip malls, city trees, and community values. Arboriculture \& Urban Forestry, Champaign, v. 35, n. 1, p. 33 - 40, 2009.

ZHANG, Y.; ZHENG, B. Trees assessments of citizen willingness to support urban forestry: an empirical study in Alabama. Arboriculture \& Urban Forestry, Champaign, v. 37, n. 3, p. 118 - 125, 2011.

ZHENG, B. Assessing urban trees and urban forests management. $130 \mathrm{f}$. Dissertação (Doutorado em Silvicultura) - Escola de Silvicultura e Ciências da Vida Selvagem, Universidade de Auburn, Auburn, 2011. 